\title{
The climate crisis is also a child rights crisis
}

Authors:

Haytham Ali, Neonatal Division, Sidra Medicine, Doha, Qatar

Alison Firth, Royal College of Paediatrics and Child Health, London, UK

Alison Leaf, Honorary Lecturer in Global Child Health, University of Bristol, UK

Cinthu Vivehananthan, Norwich Medical School, Norwich, UK

Dhurgshaarna Shanmugavadivel, Academic Unit of Population and Lifespan Sciences, University of Nottingham, Nottingham, UK

Ekundayo Ajayi-Obe, Department of Paediatrics and Neonatology, Hammersmith Hospital, Imperial College Healthcare NHS Trust, London, UK

Jay Halbert, Department of Paediatrics, Maidstone and Tunbridge Wells NHS Trust, Tunbridge

Wells, UK

Jenny Harper Gow, Gloucester Royal Hospital, Gloucester, UK

Mia Thomas, Leeds Teaching Hospitals, Leeds, UK

Paula de Sousa, Evelina Children's Hospital, London, UK

Tony Waterston, International Society for Social Pediatrics and Child Health, Newcastle upon

Tyne, UK

Bernadette O'Hare*, Senior Lecturer in Global Health, The University of St Andrews, North Haugh, St Andrews, UK

*Corresponding author: Dr Bernadette O’Hare

Keywords: climate change; child rights; child health; the determinants of health; the sustainable Development Goals, the United Nations Convention on the Rights of the Child 
The Royal College of Paediatrics and Child Health $(\mathrm{RCPCH})$ recently published a new position statement on the climate crisis ahead of the 2021 UN climate conference in Glasgow (COP26) [1]. The statement reminds us that children have the right to health, including healthcare and other fundamental economic and social rights. A child rights-based approach builds on a human rights approach but includes the specific needs of children. Furthermore, many international agreements, including the 2030 Agenda for Sustainable Development and the Paris Agreement, affirm countries' commitments to a human rights-based approach to development and climate action. Thus, the negative impacts of climate change on children trigger obligations among those responsible for both mitigation and adaptation [2].

\section{The RCPCH position statement says:}

"All children have the right to clean air, safe water, sanitation, affordable and nutritious food, and shelter. Yet millions of children in the UK and globally do not have access to these critical health determinants - a situation that will be worsened by climate change".

Air pollution will impact almost all children in all parts of the world. Nearly all children in the world breathe poor quality air and, in 2016, 300,000 children aged less than five years died because of ambient air pollution, and a further 400,000 died as a result of household air pollution [1]. Children breathe faster, so they inhale more airborne toxicants in proportion to their weight at a time when their organs are still forming. Exposure to air pollutants during pregnancy and childhood can have harmful and irreversible effects on the development of the lungs and other organs and the potential for health problems as an adult $[1,3]$.

Millions of children currently do not have access to the critical services required to meet their basic needs. Climate change will further erode these rights. Moreover, overwhelmingly, these children live in those parts of the world that have contributed the least to the climate crisis and in countries with the least resources to provide the critical services which are their right, much less to adapt current services to climate change. Indeed, many children are currently exposed to climate change-related water scarcity, heat waves, vector-borne disease, and flooding [3]. By 2030 , there could be an additional 77,000-131,000 deaths among children less than five years of malnutrition attributable to climate change. In addition, by 2040 , one in four children will be living in areas of extremely high water stress [1]. 


\section{Children's voices}

In a global leadership vacuum, children and young people worldwide have taken up the struggle and demanded action from their governments on an unprecedented and inspiring scale. They are using all tools at their disposal, including demonstrations, online activism and legal avenues to find solutions to a crisis that will impact them more than adults simply because they have their whole lives ahead of them.

For example, in 2020, six children and young people from Portugal took thirty-three countries to the European Court of Human Rights (ECtHR). They want the ECtHR to make a legally binding decision that will mandate governments to take urgent action on climate change [4].

In a landmark ruling in 2021, in response to a historic climate-related petition by sixteen children and young people, the United Nations Committee on the Rights of the Child (UNCRC) concluded that countries bear responsibility for the harmful impact of their carbon emissions on the rights of children at home and across borders. In addition, a committee member stated that "the collective nature of the causes of climate change must not absolve a State from its individual responsibility" [5]. However, despite this encouraging conclusion, the Committee explained in an open letter to the children and young people that the case was inadmissible because complaints procedures require all cases to be taken to the national courts first [6].

\section{Need for urgent, collective action}

The $\mathrm{RCPCH}$ recognises that climate change is an existential threat to the health and wellbeing of children and young people. Therefore, in October 2020, the RCPCH joined national health and academic alliances to declare a climate and ecological emergency requiring accelerated collaborative actions. Driven by paediatricians and paediatric trainees and supported by a panel of child health experts and the college management team, the RCPCH Climate Change Working Group (CCWG) was formed in 2021.

COP26 presented an opportunity to support the world's children in their quest to save their future from the impacts of climate change. As we go forward, the RCPCH joins health professionals worldwide to call on the leaders of every country to make human health central to all climate change mitigation and adaptation actions to protect current and future generations of children and young people. The countries that have contributed most to climate change need to make significant investments towards mitigation and adaptation in those parts of the world that have contributed the least. In particular, the college wants leaders to commit to the following three areas [1]: 


\section{Support and protection of children}

We call for child health to be a central theme in all climate change policy decisions. In recognition that the climate crisis is a child rights crisis, governments should mobilise and allocate the maximum available resources to protect those rights and include a child rights risk assessment as part of all climate policy decisions.

2. Mitigation to reduce the emissions associated with climate change We call for all countries to prioritise the delivery of a rapid and just transition away from fossil fuels. Children and young people are especially vulnerable to the impacts of air pollution, and exposure to poor air quality has lifelong implications for an individual's potential. Governments should strengthen targets to end the use of fossil fuels in all sectors as part of their transition to clean renewable energy sources, including the immediate cessation of all fossil fuel exploration and subsidies.

3. Adaptation to protect current and future generations of children from the impacts of climate change

We call for targeted investment in climate-resilient, low-carbon and sustainable health and education services. Growing up in a clean and safe environment is every child's right, and urgent investment in clean water, sanitation, and good hygiene practices should be prioritised to keep children thriving. It is vital that children can continue to go to school and access healthcare services despite the increasing risks presented by climate change.

Additionally, as a member of the UK Health Alliance on Climate Change, we join other UK professional bodies in supporting the following recommendations [7]:

- All countries to achieve net zero emissions by 2040 , with countries with high emissions of carbon making bigger cuts than those with low emissions

- Countries with the greatest responsibility for carbon emissions (mostly high-income countries) to transfer funds to countries that are most vulnerable to the impacts of the climate crisis, enabling them to adapt and prepare

- All fossil fuel subsidies to end (while protecting the vulnerable who may be unfairly disadvantaged) coupled with massive investment in renewable energy and storage, green infrastructure and green jobs

- All fossil fuel companies to become net zero by 2040

- All health services to become net zero as soon as possible and before 2040 


\section{Conclusion}

This climate crisis is the single biggest health threat facing humanity and is a child rights crisis. Addressing climate change requires bold and urgent action to protect current and future generations of children. COP26 has been a crucial opportunity to assess, reaffirm and strengthen existing climate change commitments made by the international community. As well as converting promises into urgent action to mitigate climate change, global solidarity on adaptation is required, including financing. Given the current environmental risks faced by many children, child health advocates must stand with children and young people to demand urgent action on climate change.

\section{Acknowledgements}

The International workstream of the RCPCH Climate Change Working Group (CCWG) would like to acknowledge the leadership of the RCPCH Climate Change Oversight Group, the input of the other four RCPCH CCWG workstreams and the RCPCH Strategic Projects Manager.

\section{References}

1 The Royal College of Paediatrics and Child Health (RCPCH). The impact of climate change on global child health - position statement. 2021. www.rcpch.ac.uk/resources/impact-climatechange-global-child-health-position-statement (accessed 8 Nov 2021)

2 Office of the United Nations High Commissioner for Human Rights (OHCHR). Analytical study on the relationship between climate change and the full and effective enjoyment of the rights of the child. 2017;07113:18.

https://www.ohchr.org/EN/Issues/HRAndClimateChange/Pages/RightsChild.aspx

3 United Nations' Children's Fund (UNICEF). The climate crisis is a child rights crisis. New York: 2021. https://www.unicef.org/media/105376/file/UNICEF-climate-crisis-child-rights-crisis.pdf (accessed 22 Sep 2021).

4 Global Legal Action Network. Portuguese Youth Climate Case v 33 Countries - Portuguese young people versus 33 countries. 2021.https://youth4climatejustice.org/ (accessed 8 Oct 2021).

5 Leiden Children's Rights Observatory Sacchi et al. v. Argentina et al.: A revolutionary climate case before the UN Child Rights Committee declared inadmissible. 2019. 
https://www.childrensrightsobservatory.nl/discussions/sacchi-et-al-v-argentina-et-al-arevolutionary-climate-case-before-the-un-child-rights-committee-declared-inadmissible (accessed 8 Nov 2021).

6 Office of the United Nations High Commissioner for Human Rights (OHCHR). Open Letter to the Authors. 2021.

https://www.ohchr.org/Documents/HRBodies/CRC/Open_letter_on_climate_change.pdf

7 UKHACC. COP26 - UN Climate Change Conference 2021 - UK Health Alliance [Internet]. 2021

Available from: http://www.ukhealthalliance.org/cop26/ (accessed 9 Nov 2021) 